\title{
Ketogenic Diet as a Non-pharmacological Treatment in Epileptic Disorders in a Tertiary Hospital
}

\author{
Margarita Castro Rey ${ }^{1 *}$, Alejandra Melero González², Selma Vázquez \\ Martín $^{2}$, Carmen Alonso Vicente ${ }^{3}$, Sara González Uribelarrea ${ }^{1}$, José \\ Manuel Marugán de Miguelsanz ${ }^{\mathbf{3}}$ and Patricia Ramos ${ }^{\mathbf{4}}$ \\ ${ }^{1}$ Department of Pediatric, Hospital Clínico Universitario de Valladolid, Spain \\ ${ }^{2}$ Department of Pediatric Neurology, Hospital Clínico Universitario de Valladolid, \\ Spain \\ ${ }^{3}$ Department of Pediatric Gastroenterology, Hospital Clínico Universitario de \\ Valladolid, Spain \\ ${ }^{4}$ Department of Nutritionist, Hospital Clínico Universitario de Valladolid, Spain \\ *Corresponding Author: Margarita Castro Rey, Department of Pediatric, Hospital \\ Clínico Universitario de Valladolid, Spain.
}

Received: April 25, 2020

Published: September 18, 2020

(C) All rights are reserved by Margarita

Castro Rey., et al.

\section{Abstract}

Ketogenic diet is a low-carbohydrate, high-fat diet used in children as a non-pharmacological treatment in different diseases (especially in drug-resistant epilepsies and congenital metabolic disorders). Our first objective was to describe the characteristics of the patients treated with ketogenic diet in a tertiary hospital, in addition to reflecting the results and its complications in a short, medium and long term.

We designed a retrospective and descriptive study, collecting children between 0 and 14 years old, who started ketogenic diet after January 2017 in our centre (at that date we designed a following-up protocol).

9 children were included. All of them (100\%) had epileptic disorders and had previously been treated with more than two antiepileptic drugs. All patients (100\%) were evaluated by a multidisciplinary team (a pediatric neurologist, a pediatric gastroenterologist and a nutritionist) in a first visit. The kind of ketogenic diet and the method of beginning were chosen depending on individual and family characteristics. The most commonly used diet was the standard ketogenic diet $(77,7 \%)$. 66,7\% of patients started the diet at home, without complications.

Out of all side effects registered, the asymptomatic or mild hypoglycaemia was the most frequently observed (100\%); followed by gastrointestinal symptoms (88.9\%) and micronutrient deficiencies $(77,78 \%)$.

Three patients $(33,3 \%)$ decided to leave the study before concluding. The main reason was the high weight loss in two of them and the lack of improvement at 12 months follow up in the other case.

As a result of the above, it was found that the majority of the children treated with ketogenic diet controlled their seizures $(88,89 \%)$, with good results in cognitive statements $(44,4 \%)$ and quality of life $(44,4 \%)$.

In conclusion it can be concluded that ketogenic diet seems to have been an effective instrument to control seizures and to produce a cognitive and functional improvement in children with drug-resistant epileptic disorders. In general, the diet has been well tolerated with a good treatment adherence. Side effects registered are in accordance with those described in other manuscripts, being the most of them slight effects. Serious complications were not registered.

Keywords: Ketogenic Diet; Epilepsy; Feeding; Seizures

\section{Introduction}

Ketogenic diet consists in feeding with low doses of carbohydrates and proteins, and high doses of fats. This diet develops a metabolic fasting state for the organism and it is used as a nonpharmacologic treatment in some diseases in children [1].
The exact way ketosis can control seizures is unknown. When reading Corpus hippocraticum book, it is mentioned fasting like a good treatment for epilepsy [2]. However, the first time we can read something published on ketogenic diet dates back to 1911 in France when Guelpa and Marie described a group of epileptic pa- 
tients who controlled their seizures with modifications on their diets [3]. After that, in 1921, Dr. Conklin allowed in the United States thirty people with pharmacoresistant epilepsy to fast for twenty days, improving their seizures. This treatment was introduced in Johns Hopkins Hospital because of its good results [2].

Subsequently, different antiepileptic drugs (AEDs) were designed later and ketogenic diet was forgotten for years.

In 1993, the ketogenic diet cured Charlie Abraham's epilepsy and it changed the mind of lots of neurologists who had dismissed the idea. Charlie's foundation in the United States and Matthew's Friends foundation in Europe are nowadays the engine of this non pharmacological treatment $[4,5]$.

Normally, with a varied and balanced diet, the human body uses carbohydrates as its first energy source. During fasting this process changes and the fats replace the carbohydrates, starting the mechanism known as lipolysis so as to obtain it. When lipolysis starts, fats and fatty acids are consumed through the beta oxidation, generating different ketone bodies (acetoacetate, beta hydroxybutyrate and acetone). These metabolites can be used as an energy source and can produce adenosine triphosphate (ATP). On the other hand, ketone bodies can cross the blood brain barrier and can be used for neuron cells to improve their nerve conduction. This condition is good not only for epilepsy, where is known that synapsis are wrong, but also for disability, learning difficulties and other comorbidities that these patients usually have [6].

There are some diseases where ketogenic diet can have evident benefits but the main and more studied indication is epilepsy. Nowadays its anticonvulsant effect is well known. We should use it when the treatment with two antiepileptic drugs (AEDs) has failed. However, it is true that there are some epileptic disorders in which ketogenic diet can be used as first line of treatment before or simultaneously with antiepileptic drugs (AEDs).

Ketogenic diet can not only control seizures, as we said previously, but also improve cognitive and behaviour difficulties in these people [7].

According to different publications, in $50-60 \%$ of patients treated with ketogenic diet the number of their seizures was reduced in half and up to $15-20 \%$ remain in a period of seizuresfreedom [8].

Another disease where ketogenic diet is the first treatment is glucose transporter type 1 (GLUT1) deficiency syndrome. It is caused by mutations in the SLC2A1 gene which produce the GLUT
1. This protein is necessary to introduce glucose into cells. When it is missing or defective, the brain, whose main energy source is glucose, is seriously affected. Ketogenic diet allows the brain to use other resources to produce energy and it can develop its skills with a normal course [9].

The ketogenic diet can also be used in obesity, autism and other diseases, but results remain discordant [10].

Regarding its contraindications, the main causes are all disorders related with fatty acids metabolism because of difficulties to carry out the lipolysis. Other contraindications could be a focal epilepsy, nutritional problems or difficulties to comply with the diet correctly.

There are four different types of ketogenic diet according to the ratio of the main meal dispensed.

The traditional, standard or "classic" ketogenic diet (SKD) is very rich in fats (almost $90 \%$ of energy ingested). Most of these fats are long chain fatty acids (LCFA), and the rest are carbohydrates and proteins. In this kind of diet, the ratio can be changed based on individual characteristics. So, it can be 4:1 (4 grams of fat for each gram of proteins and carbohydrates), $3: 1$ or $2: 1$, being the first two ratios the most used ones.

On the other hand, we have the medium-chain triglyceride (MCT) ketogenic diet. The main difference comes from the kind of fats ingested. MCT metabolism is faster than LCFA so it allows to reach ketosis with a lower ratio between fats and proteins/carbohydrates $(1,2: 1)$. The problem is that MCT is worse tolerated.

The other two diets are the modified Atkins diet (MAD) and the low glycaemic index treatment (LGIT). They are less restrictive than the aforementioned.

In the modified Atkins diet (MAD), fats and proteins can be freely eaten and just carbohydrates should be restricted. There is no calories restriction so it's easier to prepare.

In the low glycaemic index treatment (LGIT) the only condition is to eat foods with low glycaemic index $(<50)$. It provides more proteins and you can mix them with fats [11]. The main differences are summarised in table 1.

According to the text previously described, we aimed to assess the clinical outcomes of pediatric patients managed by ketogenic diet in our centre. For this reason, we decided to analyse retrospectively the clinical characteristics in our patients, their following-up and the results of this non-pharmacological treatment. 


\begin{tabular}{|l|c|c|c|c|c|c|}
\hline \multicolumn{2}{|l|}{ Type of diet } & FAT (\%) & $\begin{array}{c}\text { MCT } \\
\text { (\%) }\end{array}$ & $\begin{array}{c}\text { Proteins } \\
\text { (\%) }\end{array}$ & $\begin{array}{c}\text { CHO } \\
\text { (\%) }\end{array}$ & Relation \\
\hline \multirow{3}{*}{ SKD } & $4: 1$ & 90 & - & \multicolumn{2}{|c|}{10} & $4: 1$ \\
\cline { 2 - 7 } & $3: 1$ & 87 & - & \multicolumn{2}{|c|}{13} & $3: 1$ \\
\cline { 2 - 7 } & $2: 1$ & 80 & - & \multicolumn{2}{|c|}{20} & $2: 1$ \\
\hline \multirow{2}{*}{ MCT } & 11 & 60 & 10 & 19 & $1,2: 1$ \\
\hline MAD & $60-70$ & - & $20-30$ & 6 & $1: 1$ \\
\hline \multirow{2}{*}{ LGIT } & $35-40$ & - & $15-20$ & GI < 50 & \\
\hline
\end{tabular}

Table 1: Different types of ketogenic diet.

Analysis of results allows to correct mistakes and improves your work.

\section{Materials and Methods}

Our main aim was to describe the clinical characteristics in patients treated with ketogenic diet in a tertiary hospital, the results of this non-pharmacological treatment and the complications observed in a short and long term.

The study population included all children from 0 years to 14 years of age who started ketogenic diet in our hospital during the last 3 years, when we started to put into practice our following-up protocol in order to manage these patients.

- Inclusion criteria: All children from 0 to 14 years of age who started ketogenic diet between January 2017 and December 2019, according to this protocol.

- Exclusion criteria: All children treated with ketogenic diet before January 2017 and all children whose monitoring is also carried out in other hospitals.

The next protocol was established in January 2017 in our centre in order to guarantee the safety and the adherence to ketogenic diet in patients treated.

The main team is comprised of two pediatric neurologists, two paediatric gastroenterologists and a nutritionist.

The pediatric neurologist decided which patients could be good candidates to start the ketogenic diet. Then, a first visit is made with the pediatric gastroenterologist who decided if the patients had not contraindications to change their diets. Routine exams were requested and when we had their results, the entire team analysed the main characteristics of the patient and decided the best type of diet for each one.
In the second visit, the nutritionist explained the diet chosen to parents. We gave them a box with all the material required (a glucometer for blood sugar and ketone bodies monitoring, a weight, a book with the main qualities of foods, another book with original recipes and a schedule to complete every week. In coordination with the family we decided where the diet will be started. If the patient was not a baby, the risk of complications was not too high and we knew that the diet was understood by parents, we decided to try to get ketosis at home. If this is not the case, it is better to admit the patient to make sure they comply.

After that, controls will be made in each visit according to the next timetable (Table 2).

\begin{tabular}{|c|c|c|c|c|c|c|c|}
\hline \multirow{2}{*}{ Timetable of following-up } & \multicolumn{7}{|c|}{ Months } \\
\hline & 1 & 3 & 6 & 9 & 12 & 18 & 24 \\
\hline \multicolumn{8}{|l|}{ Nutritional evaluation } \\
\hline $\begin{array}{l}\text { Weight, tall and body mass index } \\
\text { (BMI) }\end{array}$ & $\mathrm{X}$ & $\mathrm{X}$ & $\mathrm{X}$ & $\mathrm{X}$ & $\mathrm{X}$ & $\mathrm{X}$ & $\mathrm{X}$ \\
\hline Food and liquids ingested & $\mathrm{X}$ & $\mathrm{X}$ & $\mathrm{X}$ & $\mathrm{X}$ & $\mathrm{X}$ & $\mathrm{X}$ & $\mathrm{X}$ \\
\hline $\begin{array}{l}\text { Levels of blood sugar and ketone } \\
\text { bodies }\end{array}$ & $\mathrm{X}$ & $\mathrm{X}$ & $\mathrm{X}$ & $\mathrm{X}$ & $\mathrm{X}$ & $\mathrm{X}$ & $\mathrm{X}$ \\
\hline Side effects observed & $\mathrm{X}$ & $\mathrm{X}$ & $\mathrm{X}$ & $\mathrm{X}$ & $\mathrm{X}$ & $\mathrm{X}$ & $\mathrm{X}$ \\
\hline Calibrations of the diet & $\mathrm{X}$ & $\mathrm{X}$ & $\mathrm{X}$ & $\mathrm{X}$ & $\mathrm{X}$ & $\mathrm{X}$ & $\mathrm{X}$ \\
\hline \multicolumn{8}{|l|}{ Neurological evaluation } \\
\hline Seizures timetable & $\mathrm{X}$ & $\mathrm{X}$ & $\mathrm{X}$ & $\mathrm{X}$ & $\mathrm{X}$ & $\mathrm{X}$ & $\mathrm{X}$ \\
\hline Cognitive statement test & $\mathrm{X}$ & & $\mathrm{X}$ & & $\mathrm{X}$ & & $\mathrm{X}$ \\
\hline Quality of life test & $\mathrm{X}$ & & $\mathrm{X}$ & & $\mathrm{X}$ & & $\mathrm{X}$ \\
\hline Electroencephalogram (EEG) & & $\mathrm{X}$ & $\mathrm{X}$ & & $\mathrm{X}$ & & $\mathrm{X}$ \\
\hline \multicolumn{8}{|l|}{ Routine test } \\
\hline Blood test & $\mathrm{X}$ & $\mathrm{X}$ & $\mathrm{X}$ & $\mathrm{X}$ & $\mathrm{X}$ & $\mathrm{X}$ & $\mathrm{X}$ \\
\hline Urinary test & $\mathrm{X}$ & $\mathrm{X}$ & $\mathrm{X}$ & $\mathrm{X}$ & $\mathrm{X}$ & $\mathrm{X}$ & $\mathrm{X}$ \\
\hline Metabolic test & & & $\mathrm{X}$ & & $\mathrm{X}$ & & $\mathrm{X}$ \\
\hline Abdominal ultrasound & & & $\mathrm{X}$ & & $\mathrm{X}$ & & $\mathrm{X}$ \\
\hline Echocardiogram & & & & & & & $\mathrm{X}$ \\
\hline
\end{tabular}

Table 2: Timetable of following-up in ketogenic diet.

\section{Results}

11 children started ketogenic diet during this period. Out of 11 , 2 children were excluded because of the following-up in another hospital. Finally, 9 children were studied: 6 were males $(66,7 \%)$ and 3 were females $(33,3 \%)$. The median age of children was 70 months, the youngest was 21 months old and the oldest was 123 months old. 
All patients included (100\%) had epileptic disorders: 2 patients with Dravet syndrome (22,2\%), 2 with West syndrome $(22,2 \%)$, 4 with different epileptic encephalopathies $(44,4 \%)$ and 1 with a multifocal structural epilepsy $(11,1 \%)$.

All patients (100\%) were evaluated in a pre-ketogenic diet visit. During the visit, a correct anamnesis (family and personal background), a physical exam and anthropometric measures, an evaluation of their quality life, cognitive development and their motor function or personal autonomy (self-sufficiency), were analysed.

After that, an initial study was carried out in all patients (100\%) (blood test, urinary test, metabolic study, abdominal ultrasound exam and echocardiogram).

The type of ketogenic diet was determined based on these results and the individual characteristics of the children and their families. For these reasons, 7 patients $(77,7 \%)$ were treated with the Standard Ketogenic Diet (SKD) and 2 patients $(22,2 \%)$ with the Modified Atkins Diet (MAD). The other two diets (LGI and MCT) were not chosen due to our lack of experience in their management.

In SKD group $(77,7 \%)$ we chose the ratio $2: 1$ in 3 children $(42,85 \%)$, the ratio $3: 1$ in two children $(28,57 \%)$ and the ratio $3: 2$ in one child $(14,28 \%)$.

3 patients started their diets in hospital $(33,3 \%)$ to better control the ketosis side effects. The remaining 6 children $(66,6 \%)$ started and controlled it at home.

During this period 3 children (33,3\%) decided to stop the diet. The main reason was a sustainable weight loss $(66,6 \%)$ and the other reason was the lack of effectiveness $(33,3 \%)$.

Nowadays, the average duration of the ketogenic diet is 14,56 months, in patients who continue with the treatment, with a good treatment adherence.

If complications are analysed, we can underline that everyone $(100 \%)$ presented some of them in this period.

Out of all acute complications, the most common was mild or asymptomatic hypoglycaemia (100\%), followed by gastrointestinal symptoms (nausea, constipation, diarrhoea, abdominal pain) $(88,9 \%)$.

Other complications could be observed in a medium/long term such as hyperlipidemia $(22,2 \%)$, hypercalciuria $(88,9 \%)$, hyperuricemia and hyperechoic kidneys $(22,2 \%)$, weight loss $(22,2 \%)$ and some micronutrient deficiencies $(77,78 \%)$ (Table 3$)$.

\begin{tabular}{|c|c|c|c|c|c|c|c|c|c|c|}
\hline $\begin{array}{c}\text { Micronutri- } \\
\text { ents/ } \\
\text { Patients }\end{array}$ & 1 & 2 & 3 & 4 & 5 & 6 & 7 & 8 & 9 & Total (\%) \\
\hline $\mathrm{Na}$ & & & & & & & & & & $0(0 \%)$ \\
\hline $\mathrm{K}$ & & & & & & & & & & $0(0 \%)$ \\
\hline $\mathrm{Cl}$ & & & & & & & & & & $0(0 \%)$ \\
\hline $\mathrm{Ca}$ & $X$ & & & & $X$ & & & $\mathrm{X}$ & & $3(33,3 \%)$ \\
\hline$P$ & $X$ & & & & $X$ & & & $\mathrm{X}$ & & $3(33,3 \%)$ \\
\hline $\mathrm{Mg}$ & $X$ & & & & & & & $X$ & & $2(22,2 \%)$ \\
\hline $\mathrm{Fe}$ & & & & & & & $X$ & & & $1(11,1 \%)$ \\
\hline $\mathrm{Cu}$ & & & & & & & & & & $0(0 \%)$ \\
\hline Zn & & & $\mathrm{X}$ & $\mathrm{X}$ & & & & & & $2(22,2 \%)$ \\
\hline $\mathrm{Se}$ & & & $\mathrm{X}$ & $\mathrm{X}$ & & & & & & $2(22,2 \%)$ \\
\hline $\mathrm{Mn}$ & & & & & & & & & & $0(0 \%)$ \\
\hline Mo & & & & & & & & & & $0(0 \%)$ \\
\hline FI & & & & & & & & & & $0(0 \%)$ \\
\hline I & & & & & & & & & & $0(0 \%)$ \\
\hline $\mathrm{Cr}$ & & & & & & & & & & $0(0 \%)$ \\
\hline Vit A & $\mathrm{X}$ & & $X$ & & & & & & & $2(22,2 \%)$ \\
\hline Vit D & $\mathrm{X}$ & & $X$ & $\mathrm{X}$ & $\mathrm{X}$ & & & $\mathrm{X}$ & & $5(55,5 \%)$ \\
\hline Vit E & $\mathrm{X}$ & & $X$ & & & & & & & $2(22,2 \%)$ \\
\hline Vit C & $X$ & & $X$ & & & & $\mathrm{X}$ & & & $3(33,3 \%)$ \\
\hline Vit $\mathrm{K}$ & & & & & & & & & & $0(0 \%)$ \\
\hline Thiamine & & & & & & & & & & $0(0 \%)$ \\
\hline Riboflavin & & & & & & & & & & $0(0 \%)$ \\
\hline Niacin & & & & & & & & & & $0(0 \%)$ \\
\hline Vit B6 & $\mathrm{X}$ & & $\mathrm{X}$ & & & & & & & $2(22,2 \%)$ \\
\hline Folic acid & & & & & & & $X$ & & & $1(11,1 \%)$ \\
\hline Vit B12 & $X$ & & $X$ & & & & & & & $2(22,2 \%)$ \\
\hline $\begin{array}{l}\text { Pantoth. } \\
\text { acid }\end{array}$ & & & & & & & & & & $0(0 \%)$ \\
\hline Biotin & & & $X$ & & & & & & & $1(11,1 \%)$ \\
\hline Choline & & & & & & & & & & $0(0 \%)$ \\
\hline
\end{tabular}

Table 3: Micronutrient deficiencies observed in patients treated with ketogenic diet.

Hospital admission was not required to manage the complications. Other side effects were not detected.

The results of this non pharmacological treatment were satisfactory. Following Huttenlocher's criteria, seizures were controlled in $88,89 \%$ of cases (Table 4 ).

Ketogenic diet improved the cognitive statement in the $44,4 \%$ of children treated. It could be registered in patients younger than 


\begin{tabular}{|l|c|c|}
\hline \multicolumn{3}{|c|}{ Huttenlocher's criteria } \\
\hline \multicolumn{1}{|c|}{ Control } & Seizures reduction (\%) & Patients (\%) \\
\hline Excellent & $100 \%$ & $3(33,3 \%)$ \\
\hline Very good & $>90 \%$ & $3(33,3 \%)$ \\
\hline Good & $50-90 \%$ & $1(11,1 \%)$ \\
\hline Regular & $<50 \%$ & $1(11,1 \%)$ \\
\hline Not response & Without changes & $1(11,1 \%)$ \\
\hline Negative effect & Increase seizures & $0(0 \%)$ \\
\hline
\end{tabular}

Table 4: Seizures control according to Huttenlocher's criteria.

four years old with the Denver developmental screening test, and in patients older than four years old with the Kaufman Brief Intelligent test (K-BIT). Quality of life improved in the $44,4 \%$ of children and families according to the Health Quality of Life Questionnaire for the epileptic child (CAVE).

$66,6 \%$ patients were satisfied with the results. In the remaining $33,3 \%$ of cases the patients were not satisfied due to the early stop of the diet.

\section{Discussion and Conclusion}

The ketogenic diet is a useful instrument as a non-pharmacological treatment in the management of different diseases, being the most studied the drug-resistant epilepsy. The neuromodulator effect of fasting has been known for a long time, but it is now in the $21^{\text {st }}$ century when it gets back to regain the importance it once had [12].

There are different types of diets, based on the composition of foods that it can be eaten. It allows us to choose the better diet according to the patient. Before starting the diet, it is very important to analyse each situation, including personal and family characteristics, as well as a full examination where other disorders could be identified [13].

It's necessary to make an extra effort to make sure families understand all aspects about the diet chosen and it's vital to underline the role of the nutritionist in the multidisciplinary team. This point is very important because people have to familiarize themselves with foods, amounts and they have to change their eating habits. It's important that the best diet will be selected for each situation, in order to guarantee a good treatment adherence and thus avoid the loss of patients [14].

Once the diet has started it's crucial to make a correct followingup. Routine exams should be done during monitoring. Side effects and complications should be identified and treated. If they are dan- gerous or if there is no possible solution for the problem, the diet must be finished $[15,16]$.

Our study reflects-the management and monitoring in patients treated with ketogenic diet in a tertiary hospital. We can observe how thanks to an exhaustive following-up carried out by a multidisciplinary team, all side effects observed were slight and how they could be solved without problems. Serious complications were not registered. However, $33,3 \%$ of patients decided to stop the diet before concluding.

In general, we achieved satisfactory results with a reduction in the number of seizures in $88,89 \%$ as well as a cognitive-behavioural symptomatic effect in $44,4 \%$.

The published literature has shown similar results to our study, provided that a following-up in patients has been done correctly.

In conclusion we can say that ketogenic diet seems to have been an effective instrument to treat epileptic patients. Our results suggest that we should continue to use ketogenic diet in epileptic patients because it has good results, it has not many complications and it is usually totally accepted by the families.

In many cases it seems to be a possibility to use it as a second line of treatment, before others antiepileptic drugs.

For these reasons, other prospective studies with more patients involved are needed, classified by different pathologies, which would allow experts to draw more comparable and precise conclusions.

\section{Bibliography}

1. Lee PR and Kossoff KE. "Dietary treatments for the epilepsy: management guidelines for the general practitioner". Epilepsy Behavior 21.2 (2011): 115-121.

2. Wheless JW. "History and origin of the ketogenic diet". En: Stafstrom CE, Rho JM, editors. Epilepsy and ketogenic diet. Totowa NJ: Humana Press (2004): 31-50.

3. Guelpa G and Marie A. "La lutte contre l'épilepsie par la désintoxication et par la rééducation alimentaire". Rev Ther MedicoChirurgicale 78 (1911): 8-13.

4. Freeman JM., et al. "The epilepsy diet treatment: an introduction to the ketogenic diets". 2 ed. New York: Demos (1996).

5. Titre-Johnson S., et al. "Ketogenic diet in the treatment of epilepsy in children under the age of 2 years: study protocol for a randomised controlled trial". Trials 18 (2017): 195 
6. Maalouf M., et al. "The neuroprotective properties of calorie restriction, the ketogenic diet, and ketone bodies". Brain Research Reviews 59 (2009): 293-315.

7. Bough KJ and Rho JM. "Anticonvulsant mechanisms of the ketogenic diet". Epilepsia 48 (2007): 43-58.

8. Carballo R., et al. "Long-term follow-up of the ketogenic diet for refractory epilepsy: multicentre Argentinean experience in 216 pediatric patients". Seizure 20 (2011): 640-645.

9. Pearson TS., et al. "Phenotypic spectrum of glucose transporter type 1 deficiency syndrome (Glut1 DS)". Current Neurology and Neuroscience Reports 13.4 (2013): 342.

10. García-Peñas JJ. “Trastornos del espectro autista y epilepsia: el papel de la dieta cetogénica". Revista de Neurología 62 (2016): S73-78.

11. Kim JA., et al. "Efficacy of the classic ketogenic and the modified Atkins diets in refractory childhood epilepsy". Epilepsia 57.1 (2016): 51-58.

12. Cross JH., et al. "The ketogenic diet in childhood epilepsy: where are we know?" Archives of Disease in Childhood 95 (2010): 550-553.

13. Armeno M., et al. "Consenso nacional sobre dieta cetogénica". Revista de Neurología 59.5 (2014): 213-223.

14. Bergqvist AG., et al. "Fasting versus gradual initiation of the ketogenic diet: a prospective, randomized clinical trial of efficacy". Epilepsia 46.11 (2005): 1810-1819.

15. Ballaban-Gil K., et al. ". Complications of the ketogenic diet". Epilepsia 39.7 (1998): 744-748.

16. García-Peñas JJ. “Epilepsia, cognición y dieta cetogénica”. Revista de Neurología 66 (2018): S71-S75.

\section{Assets from publication with us}

- Prompt Acknowledgement after receiving the article

- Thorough Double blinded peer review

- Rapid Publication

- Issue of Publication Certificate

- High visibility of your Published work

Website: www.actascientific.com/

Submit Article: www.actascientific.com/submission.php Email us: editor@actascientific.com

Contact us: +919182824667 